Available online at: https://specedjournal.aspu.am/index.php/se

DOI: $10.24234 /$ se.v5i1.285

\title{
COMPARATIVE ANALYSIS OF QUANTITATIVE INDICATORS OF THE PEDAGOGICAL-PSYCHOLOGICAL SUPPORT TEAMS'ACTIVITIES IN ARMENIA
}

\begin{abstract}
AUTHORS' DATA
Marianna Harutyunyan, EU MSc OT, PhD in Education, Associate Professor

Chair of Speech and Rehabilitative Therapy

Khachatur Abovyan Armenian State Pedagogical University, Republic of Armenia

Contacts: marianna.harutyunyan@aspu.am
\end{abstract}

Araksia Svajyan, $\mathrm{PhD}$ in Education, Associate Professor

Republican Pedagogical-Psychological Centre, Principal, Republic of Armenia

Contacts: araksya-svajyan@rambler.ru

Shushanik Antonyan, MA in Education Management

Specialized Children's Home of Kharberd, Republic of Armenia

Contacts: sh.antonyan@gmail.com

\begin{abstract}
The following study aims to describe and compare the action of pedagogicalpsychological support teams within the scope of new functions stated after recent reforms taking place in the Armenian education system. Three regions were selected as pilots within the reforms towards universal inclusive education.

Within the frame of the current study quantitative methodology pursues to compare three regions for a few result variables. Participants of this research are parents of children with special educational needs $(n=440)$, and pedagogical-psychological support team members $(\mathrm{n}=85)$ living in Tavush, Lori, and Syunik regions.

In general results of the study reveal the need for pedagogical-psychological support teams and relevant specialists in schools, which is confirmed by the teachers, parents, and teachers' assistants at the school. To hand are some problematic issues between support centers and parents related to the child's further education. Also, serious conflicts with the parents, as the issues of further education of the child involved in inclusive education are not clarified, remain to be on the list.
\end{abstract}

Keywords: universal inclusive education, pedagogical-psychological support team, pedagogical-psychological support service, parents of children with special educational needs, school, education, teacher, teacher assistant. 


\section{INTRODUCTION}

To implement the policy of universal inclusive education in the Republic of Armenia, following Article 17.1, Clause 1 of the Law of the Republic of Armenia on General Education, pedagogical-psychological support services for learner education are provided at three levels: School level, regional level, and national level (RA Minister of Education and Science Order N 370-N of April 13, 2017).

At the school level, services are provided to learners who have been duly assessed and identified as having special educational needs. At this level, the services are provided by the pedagogical-psychological support service of the general educational institution (teacher assistant, special pedagogue, psychologist, social pedagogue-nurse). The duration, scope, and provision schedule of support services provided to each learner with special educational needs are developed by the support team of the institution, approved by the principal, who is responsible for ensuring the quality and efficiency of the services. If there is a shortage of the mentioned specialists in the institution, they are invited by the Regional Center serving the given institution (Order N 370-N, point II of the RA Minister of Education and Science of April 13, 2017).

At the regional level, the services are provided by the regional center for pedagogicalpsychological support based on the application of the directorate of the secondary education institution or the child's parent/ legal representative. Regional Center specialists visit the school and assist the school support team in developing support services for the learner. In case of a child not attending school/kindergarten/, support is organized at the Regional Center.

After the approval of the Individual Learning Plan, the school principals of the Regional Center and school jointly sign and validate the volume of services provided by the Regional Center to the school (learner, teacher, parent), the schedule and the schedule of the Regional Center's specialists to attend school. In addition, when making the schedule, it should include specialists visiting the school at least once a week. The schedule is attached to the Individual Learning Plan.

If the service provided to the learner requires appropriate adapted space, equipment, and facilities, the Regional Center may, with the consent of the parent, provide the support services based on the Individual Learning Plan of the child. The provision of services to the child in the Regional Center is carried out free of charge, with the funds of the regional Center, after classes, according to the planned duration and volume. At the end of each day, the staff providing support services to the Regional Center records the work done in the relevant sections of the individual curriculum (Order N 370-N, point II of the Minister of Education and Science of April 13, 2017). 
The regional center provides the necessary consultancy and professional support on the organization of learner education to the learner's parent, members of the school pedagogicalpsychological group, and teachers, providing constant communication between parents, professionals, and teachers in the form of mutual visits, telecommunications, online consultancy (Order N 370-N of 13, point III RA Minister of Education and Science of April 13, 2017). In cases where the analysis of the child's school-level assessment results indicates the likelihood of a child having functional impairment, the institution, with the parent's consent, applies to the Regional Center for a regional-level assessment. Regional level assessments can also be made directly at the request of the parent.

By the order of the Regional Center director, a group of pedagogical staff is formed in the educational institution to assess the child at the regional level, which includes at least 3 specialists of the regional Center: a special pedagogue, a psychologist, and a social pedagogue. This assessment lasts for at least a week, after which the child assessment protocol and the assessment conclusion are developed and submitted (Order N 370-N, point III of the Minister of Education and Science of the Republic of Armenia of April 13, 2017).

\section{METHODOLOGY}

Quantitative methodology seeks to compare three regions for few outcome variables (Doody \& Bailey, 2016). The quantitative approach is based on developed questioners and tend to be precise and can be categorized as comparative Applicable questions highlight the respondents, dependent variables and design (causal-comparative), and the link between the research question and the design (Onwuegbuzie \& Leech 2006; Kloda \& Bartlett 2013).

Participants of these research are parents of children with special educational needs $(n=440)$, and pedagogical-psychological support team members $(n=85)$ living in Tavush, Lori and Syunik regions.

\section{DATA ANALYSES AND RESULTS}

The data presented in the table below provide an opportunity to refer to the qualitative facts in digital terms, that is, is it possible for such a small support team to provide qualified services to children with special educational needs, and at the same time follow the type and period of planned support services defined by Order N 370-N of the RA Minister of Education and Science of April 13, 2017. The conclusion here is one - definitely not. This viewpoint is shared by both the directors and the members of the support team of all the regional 
Pedagogical-Psychological Support Centers of the target regions that participated in the qualitative research.

At the same time, the same order, as part of the support, separately mentions environmental adjustments, which include customized items and technologies for everyday use, assistive devices, accessible literature, Braille books, manuals, and audio materials, largeformat material, simplified and easy perceptible and legible material, movable and immovable ramps at entrances and exits, wide doors, thresholds at the floor, adapted toilets, special markings, technologies), equipment and technologies to assist a person with mobility, as well as support for others and extra time. All this should have been the basis for universal inclusion, and the overall process should have been built on existing resources. However, today, three years later, environmental adjustments in schools and support centers are either completely absent or present in very small quantities.

\section{Table1.}

The data in the table presents the number of support professionals and children receiving services in three regions

\begin{tabular}{|l|c|c|}
\hline Center by location & Number of assistants & $\begin{array}{l}\text { Number of children } \\
\text { receiving service }\end{array}$ \\
\hline \multicolumn{3}{|c|}{ Tavush region } \\
\hline Dilijan & 8 & 78 \\
\hline Jjevan & 14 & 212 \\
\hline Berd & 9 & 80 \\
\hline Noyemberyan & 11 & 87 \\
\hline \multicolumn{3}{|c|}{ Lori Region } \\
\hline Spitak & 30 & 123 \\
\hline Vanadzor & 26 & 357 \\
\hline Stepanavan & 27 & 223 \\
\hline Alaverdi & 13 & 200 \\
\hline \multicolumn{2}{|c|}{ Syunik Region } \\
\hline Sisian & 21 & 118 \\
\hline Goris & 22 & 128 \\
\hline Kapan & 23 & 136 \\
\hline
\end{tabular}

The above-mentioned becomes a subject of serious consideration for both state and nonstate institutions of the Republic of Armenia, which operate within the framework of inclusive education, social and educational issues of children with special educational needs and or disabilities.

One of the preconditions for the effective implementation of any activity related to universal inclusive education is the availability of appropriate environmental conditions, which 
presupposes the availability of appropriate conditions for the geographical and physical location, movement, and relocation of the relevant facility.

From this point of view, the availability of the geographical location of the regional pedagogical-psychological centers of the Tavush, Lori, and Syunik regions have been studied according to the ratio of the distance between the center and the settlement (Figure 1, 2, 3).

Most of the surveyed parents in all target regions (Tavush region: fathers $45.5 \%$, mothers 36.6\%; Lori region: fathers 87.5\%, mothers 73\%; Syunik region: fathers $77.8 \%$, mothers $31.9 \%$ ) considered the geographical location of the Pedagogical-Psychological Support Center unfavorable in the context of the ratio between the settlement and the center. The abovementioned indicators give rise to quite serious reflections, as the qualitative indicators prove that children with special educational needs visit the regional pedagogical-psychological center only in the Tavush region. While in Lori and Syunik regions, these children mostly receive services at school during visits by support team members. The fact should also be taken into account that children with special educational needs in urban areas receive services at school twice a week, while in rural areas these children receive services only once due to barriers to specialist visits.

The free observation also allowed to reflect on the geographical location of the regional pedagogical-psychological centers and the accessibility of the road leading to those centers. It should be noted that the special schools, which were reorganized into regional centers and built during the Soviet era, are quite far from the settlements, even within the city. Examples of such centers are the regional centers of Vanadzor, Alaverdi, Stepanavan, Kapan, which are difficult to reach not only by private transport (public transport does not work) but also almost inaccessible on foot.

\section{Figure 1.}

Geographical location of the Tavush Region Support Center (distance of the center from place of residence).

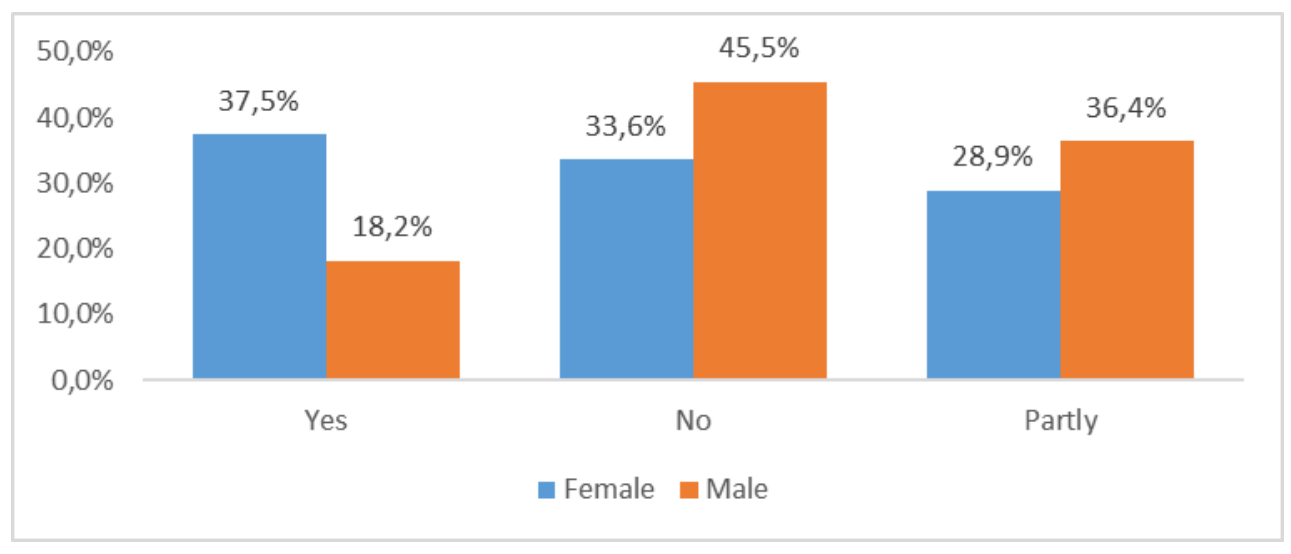




\section{Figure 2.}

Geographical location of the Lori Region Support Center (distance of the center from place of residence).

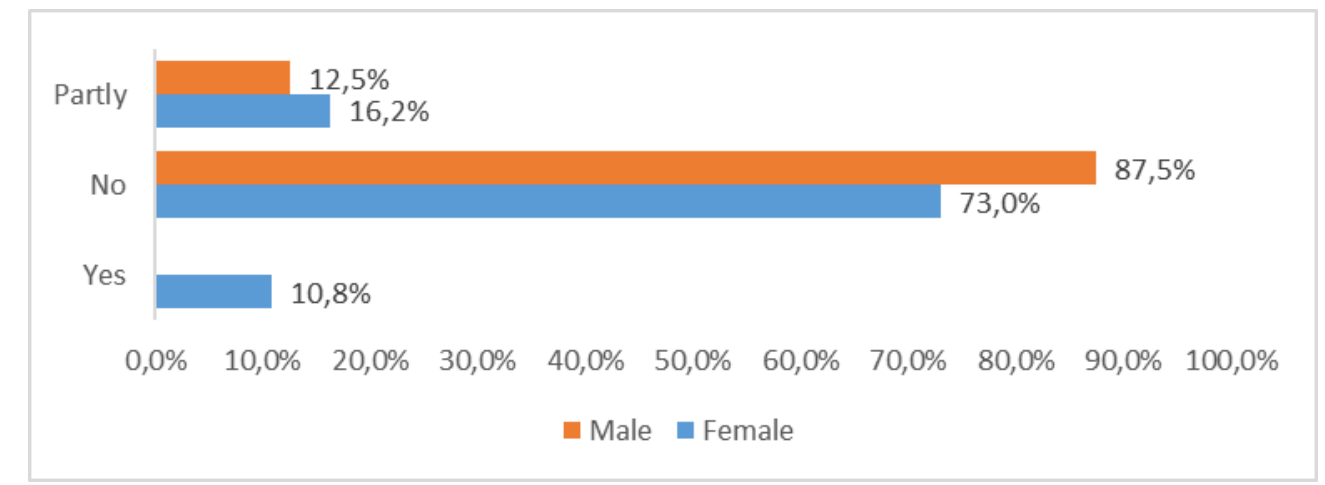

\section{Figure 3.}

Geographical location of the Syunik Region Support Center (distance of the center from place of residence).

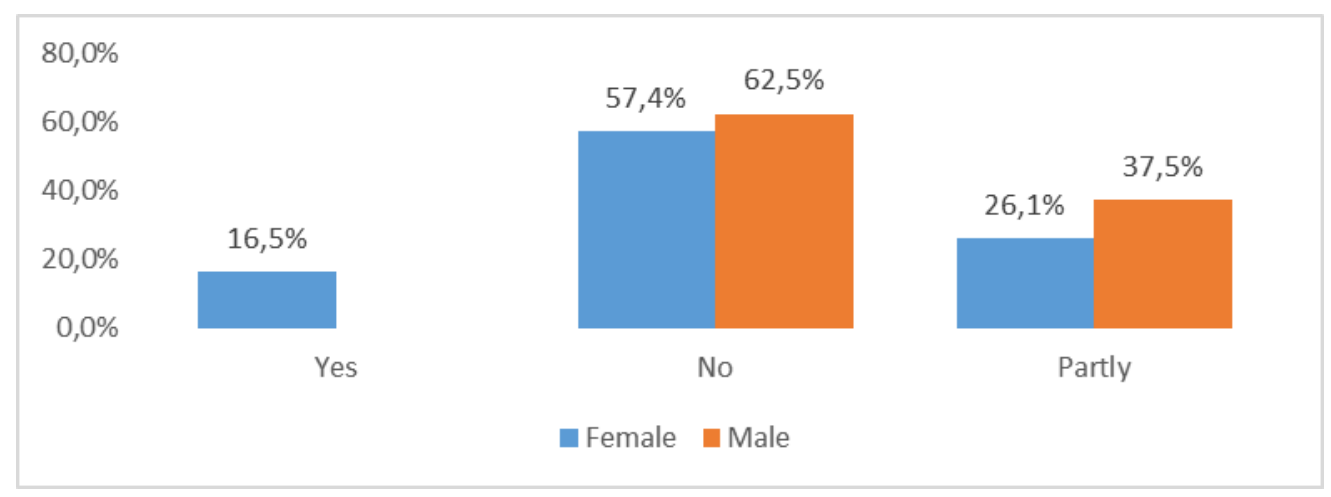

Taking into account the position of the regional pedagogical-psychological support centers, quantitative and qualitative research was conducted to study the peculiarities of the multidisciplinary team of these centers, their obstacles, and the factors influencing them. It is noteworthy that in all target regions, the number of women in the gender and age group of the multidisciplinary team was predominant $(97.4 \%)$. Moreover, the age limit of the majority fluctuates between 21-40 years old (see Table 2). 


\section{Table 2.}

\section{Gender composition.}

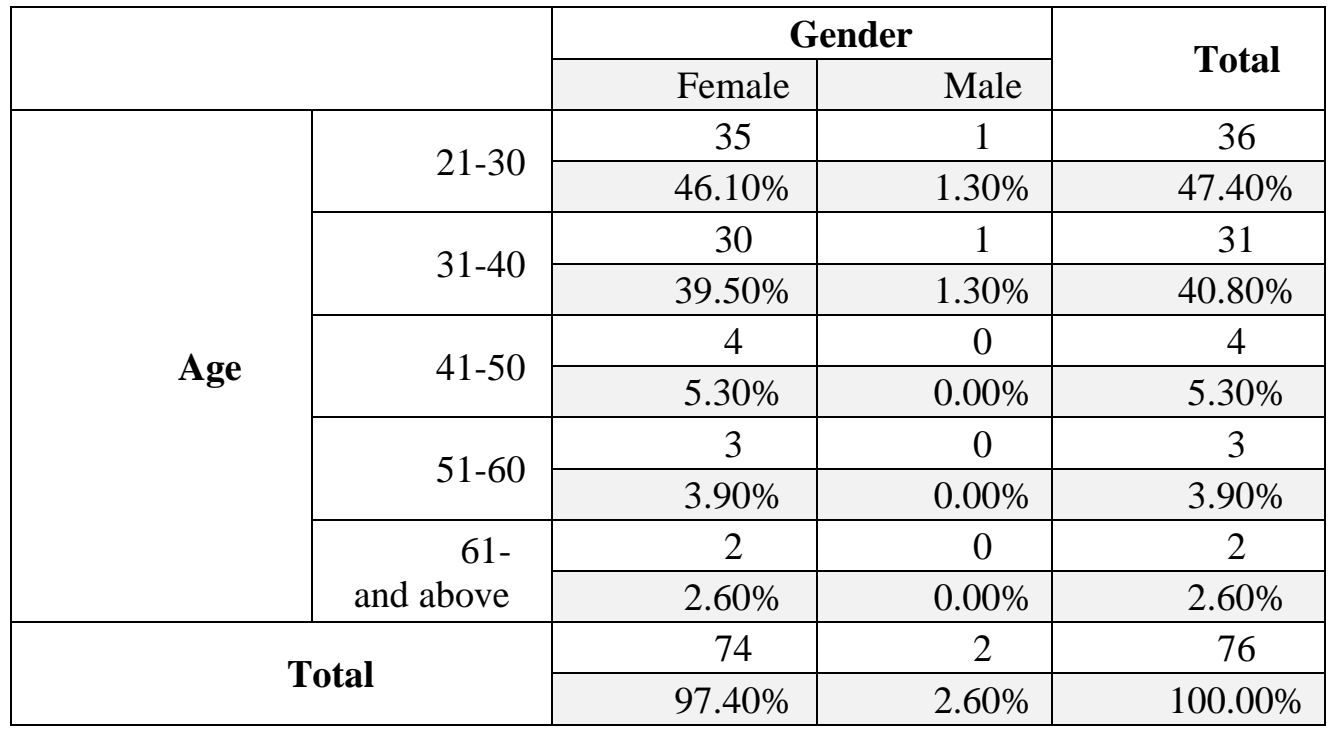

Regarding the profession of the respondents, the majority of the specialists included in the pedagogical-psychological support team of the regional centers were pedagoguepsychologists (36.8\%), psychologists $(17.1 \%)$, and social pedagogues (11.8\%). It is noteworthy that according to the adopted regulation, the team of the Regional Pedagogical-Psychological Center provides support services to children with mostly certified special educational needs, with moderate, severe, and profound developmental disabilities, based on which specialists providing special pedagogical services: speech therapist, oligophrenic pedagogue, deaf educator, special pedagogue should have made up the bulk of the team, however, research shows that the presence of these professionals in the team is small (see Figure 4).

\section{Figure 4.}

Distribution of professions of specialists working in regional centers by gender

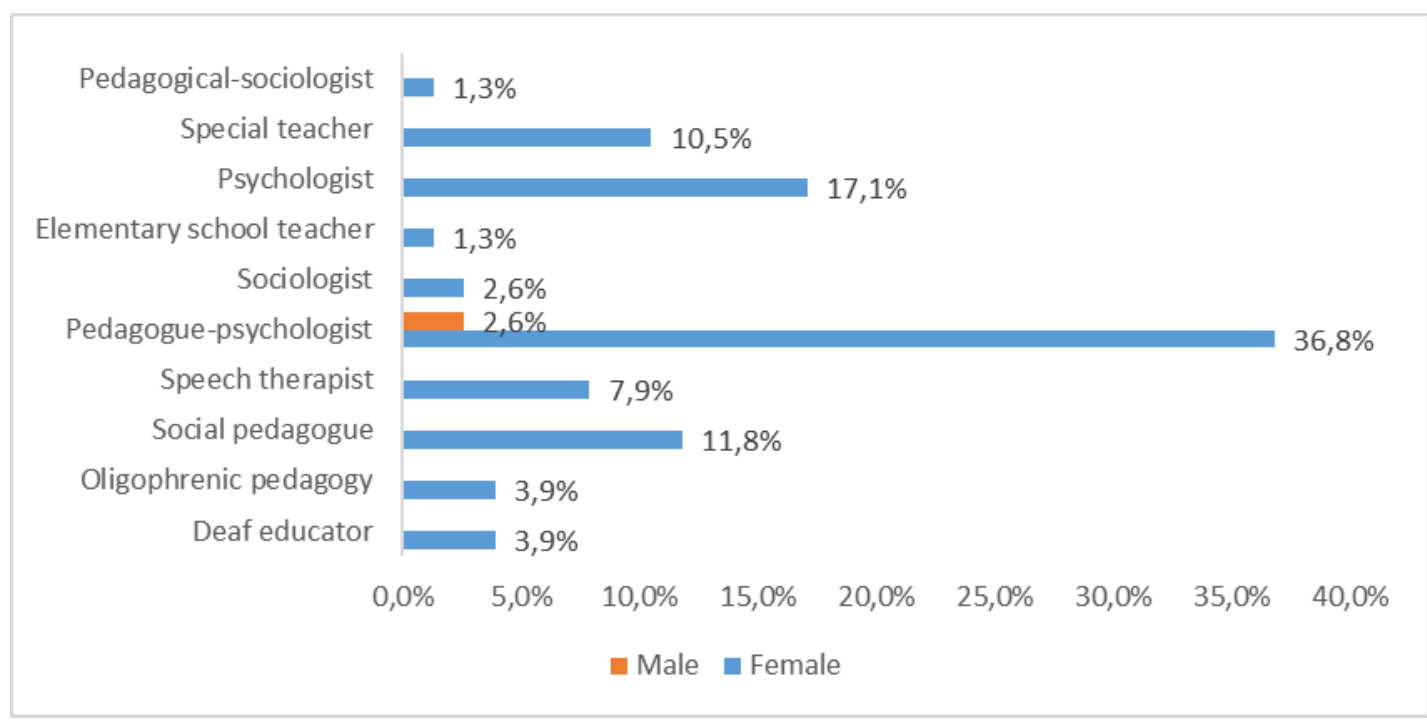


Given the fact that the Regional Pedagogical and Psychological Support Centers serve an average of 158 certified children with developmental disabilities, it is interesting to consider the average number of children receiving services per day.

The figures presented in the table show that the majority of center specialists $(58 \%)$ serve 1-3 children daily. Moreover, these services are mainly provided by a special pedagogue, psychologist, social worker and a specialist or pedagogue providing pedagogical-psychological support services. It should be added that referring to the qualitative research data, it becomes obvious that the support/special work with each child lasts on average 35-50 minutes.

On the other hand, according to experts, the work carried out under the established time norms may sometimes not fix the expected result due to the child's characteristics, socioeconomic and socio-cultural factors, for which the specialist has to break organizational norms to increase the effectiveness of support. At the same time, within the framework of the qualitative research, the respondents were not even able to clarify the scope and functions of the specialist or pedagogue providing pedagogical-psychological support services $81.08 \%$ of the total support staff participated in the training aimed at improving the skills and professional qualities of the service providers serving these children, the frequency of which is shown in Figure 5. The figures in the chart show that the majority of respondents (36\%) attend training twice a year (See Figure 5). The training of other specialists is carried out spontaneously, as needed, through self-education, not so often, which indicates that there is no clear institutional orientation on this issue.

Regarding the content of the training, it should be noted that the majority of specialists give importance to the need for practical work and new methods (22\%), training on speech disorders (22\%). The need for training with children with special education needs (21\%) on social-pedagogical and practical work (11\%), as well as courses on autism (12\%) was also mentioned as a current topic of training.

Based on the wording of the sectoral definitions of training, it can be stated that the specialists do not have a clear idea of the sectoral divisions; they separated the work organized with children with behavioral disorders from the peculiarities of the work with children with autism. The participants did not clarify the thematic differences between the training for children with complex and multiple problems or with special educational needs, citing the latter as a separate area. 


\section{Figure 5.}

\section{Frequency of participation in trainings.}

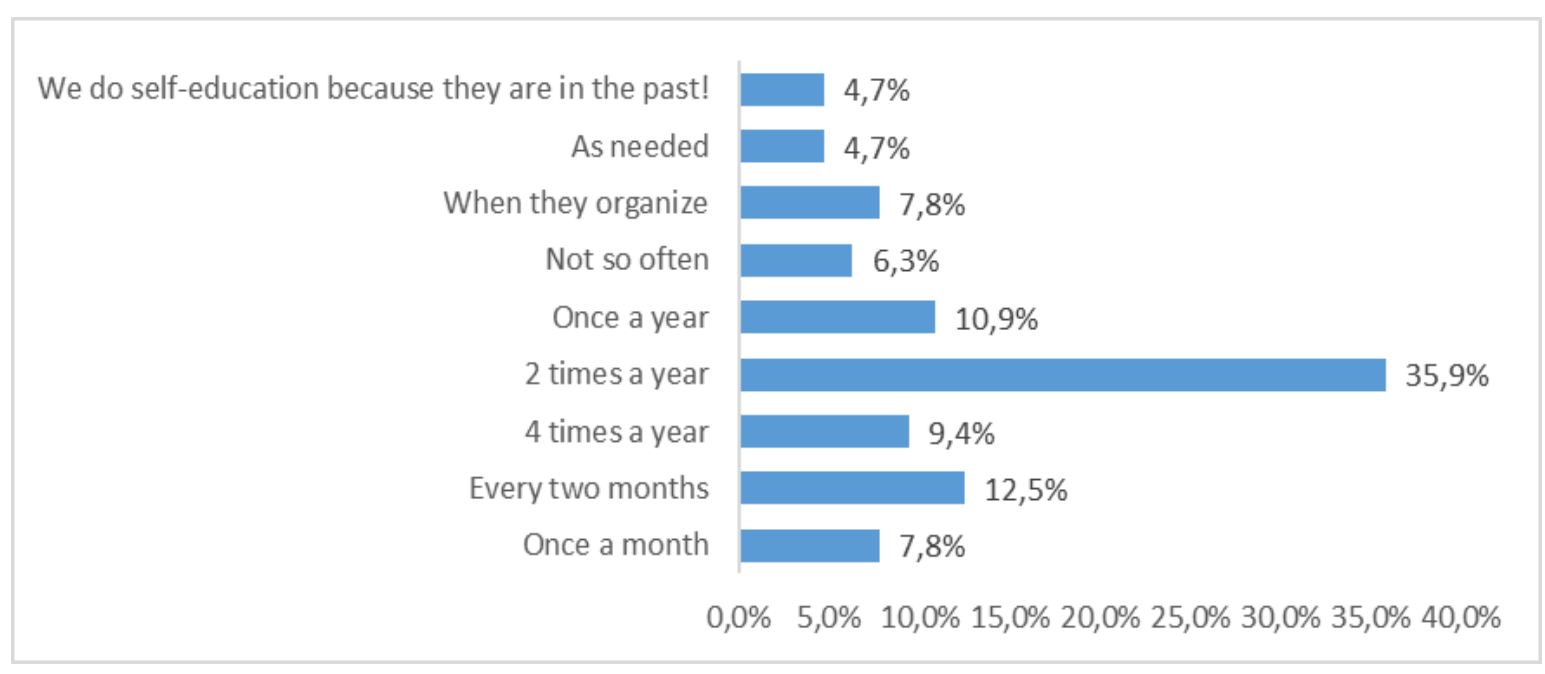

Analyzing the problems arising in the process of supporting a child with special educational needs, the conditions for the effective organization of inclusive processes necessary for school, separated by a multidisciplinary team, are especially noteworthy. Moreover, special emphasis is given to physical environment adjustment (28.4\%), professional seminars and training (13\%), reorganization of schools, professional and environmental re-equipment under the standards of inclusive education (12.4\%), development of awareness on inclusive education (8.3\%), availability and access of didactic materials and manuals (7.1\%) (See Figure 6).

Contrary to these grounded arguments, only $4.7 \%$ of respondents stressed the need to clarify the relevant education and functions of a teacher's assistant, and only $2.4 \%$ stressed the low number of special education conditions in the classroom.

From this analysis, it is necessary to address the need for training and themes necessary for the effective organization of inclusive education processes, and the results of the surveys conducted within it highlight the following picture (see Figure 7). The majority of respondents (24.2\%) need training on behavioral disorders, after which the specialists of the Support Center mention the importance of training on speech disorders, especially stuttering and general speech impairment (21\%). As for the need for training on autism, it was highlighted by $14.5 \%$ of respondents. 


\section{Figure 6.}

\section{Indicators of effectively organizing of inclusive processes at school.}

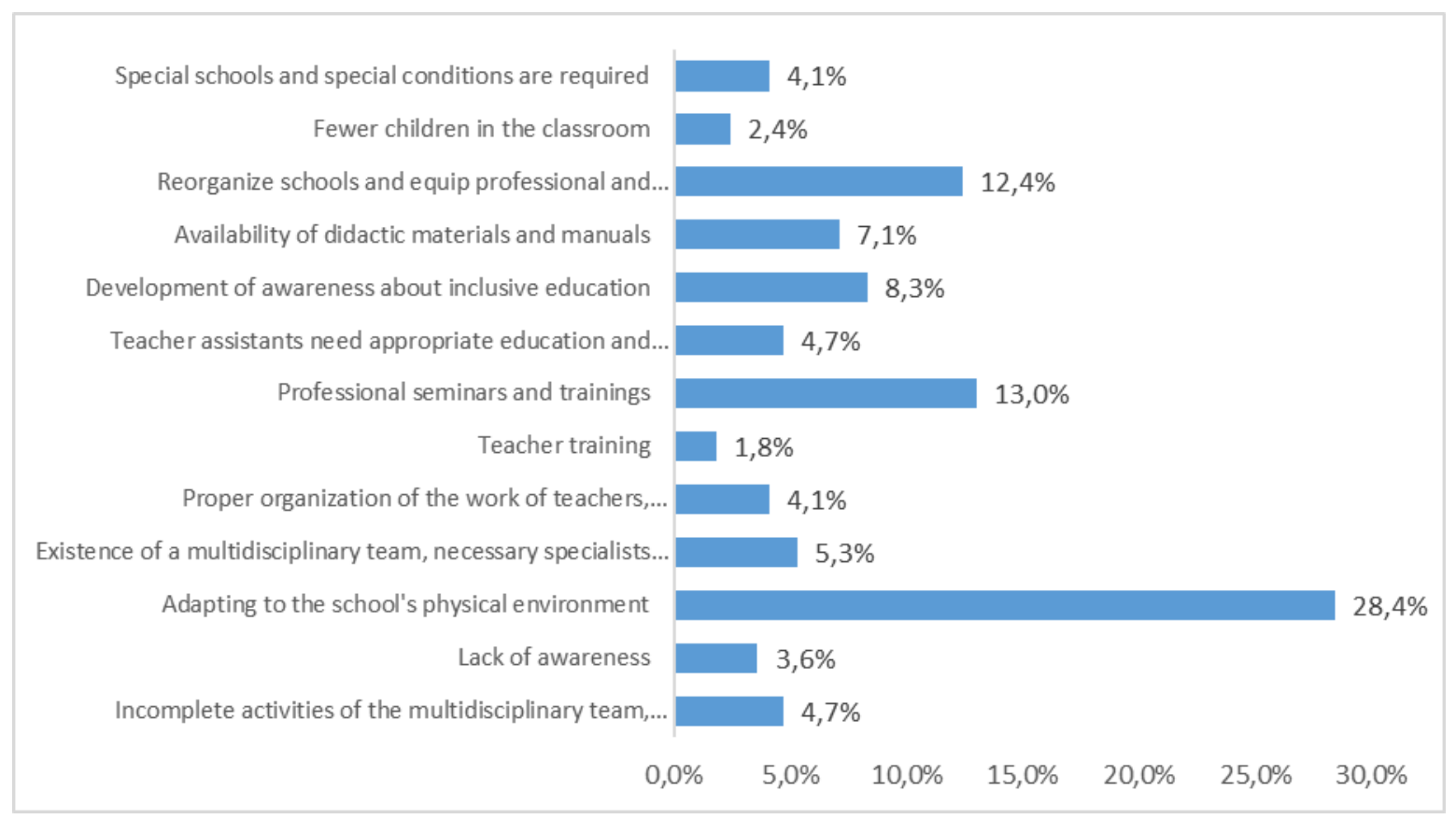

\section{Figure 7.}

\section{Needed trainings and topics.}

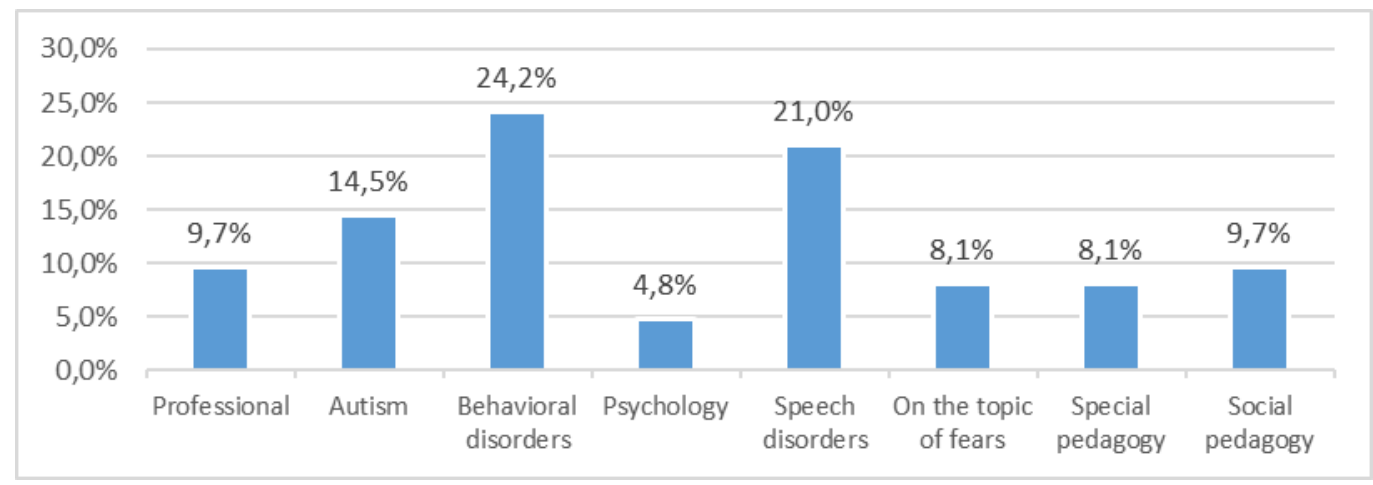

The summary of the results on the problems arising in the process of supporting a child with special educational needs allows concluding that difficult access to educational materials (31.4\%) and lacking special physical conditions (28.4\%), difficulties in working with parents $(14.7 \%)$ Obstacles $(13.7 \%)$ are quite significant in terms of obstructing the work of a multidisciplinary team, which underscores the need for appropriate resources or support tools to improve the quality of this team, according to the results of the survey definitive data. That is, the need for didactic materials (18.5\%) and professional literature, methodological manuals, guidelines (15.7\%), availability of environmental adjustment and technical equipment (15.7\%), tools to facilitate the work $(6.5 \%)$, and the Importance of new developmental games $(5.6 \%)$. (See Figure 8). 


\section{Figure 8.}

Main problems of children with special educational needs in the support process.

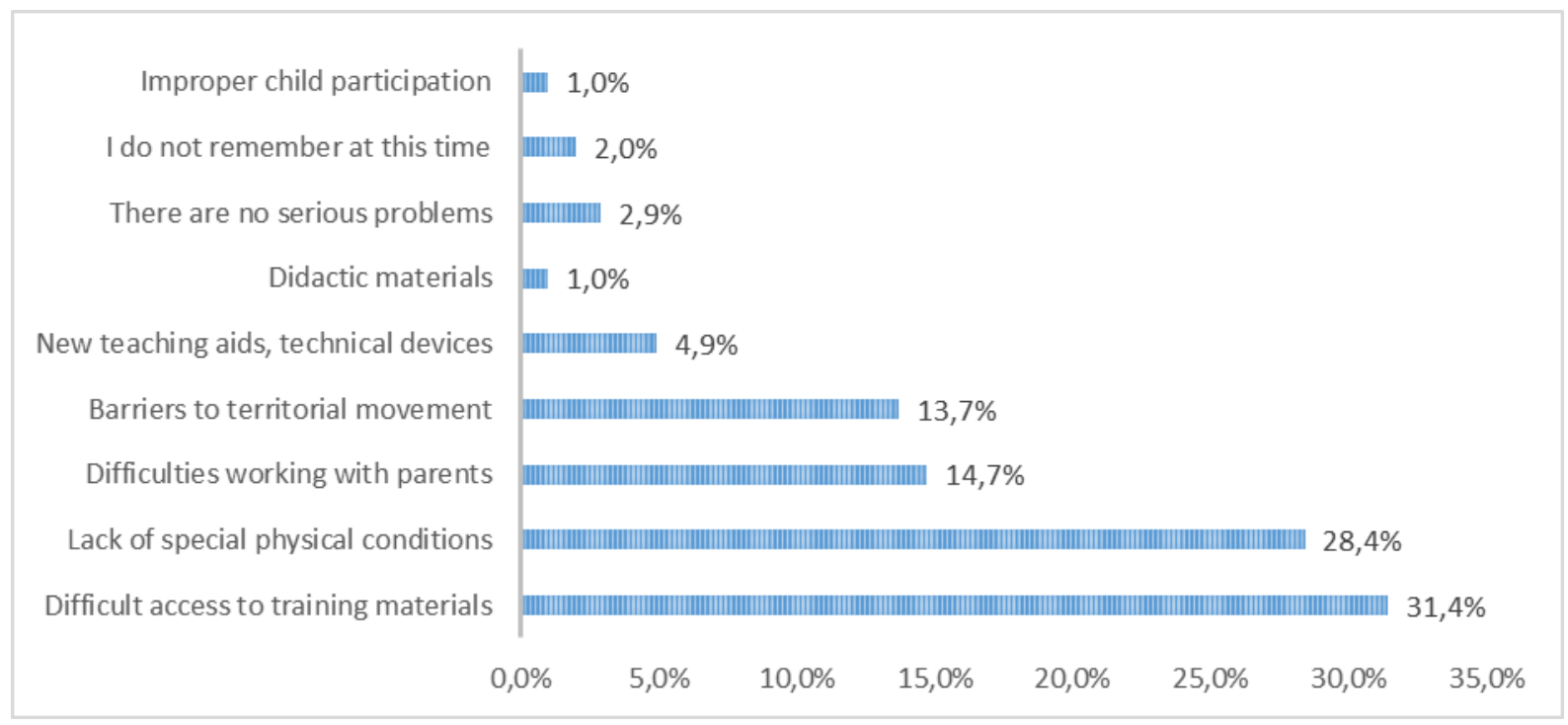

In contrast to the above percentage, only $3.7 \%$ of the specialists supporting the regional centers highlighted in quantitative research the activities of specialists needed to improve the quality of work as an important resource. (See Figure 9) Meanwhile, almost everyone mentioned in the qualitative data collection that the support team was very small, which directly affects the quality of the services provided, this was raised by both the directors of the regional pedagogical and psychological support centers, the support specialists and the school principals and teacher assistants. In fact, this is evidenced by the ratio of the number of specialists in the regional support centers, compared to the number of children in need of support. For example, Vanadzor regional center has 26 support specialists who serve 357 children in need of support.

\section{Figure 9.}

Resources or support tools for improving the work quality.

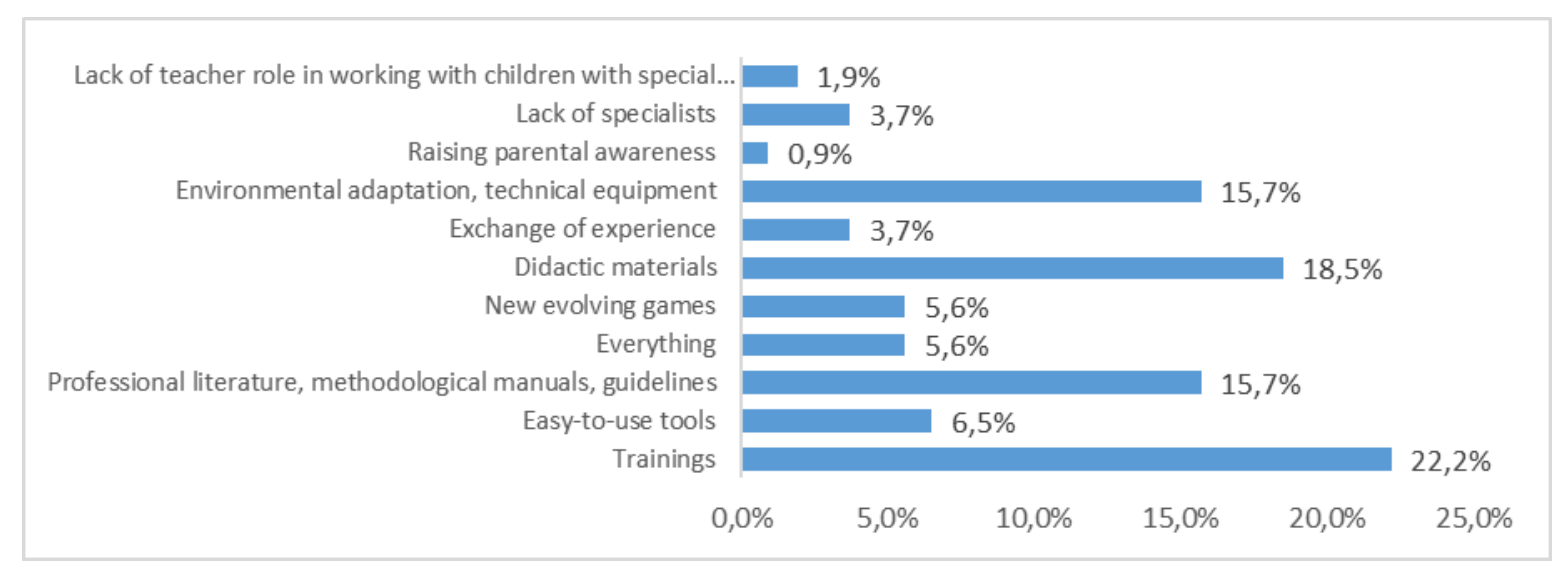


Surveys to identify difficulties in using the services of the Regional Assistance Center allowed to reveal the following picture. The majority of parents consider the distance from the center $(62.6 \%)$ as the biggest obstacle to using the services of the regional center, then they mention the insufficient proficiency of the professional team $(24.2 \%)$, and the lack of awareness about the activities of the support center as a factor. indicates $9.1 \%$ of respondents (see Figure 10).

\section{Figure 10.}

\section{Difficulties faced by the parent and child while using the regional support center.}

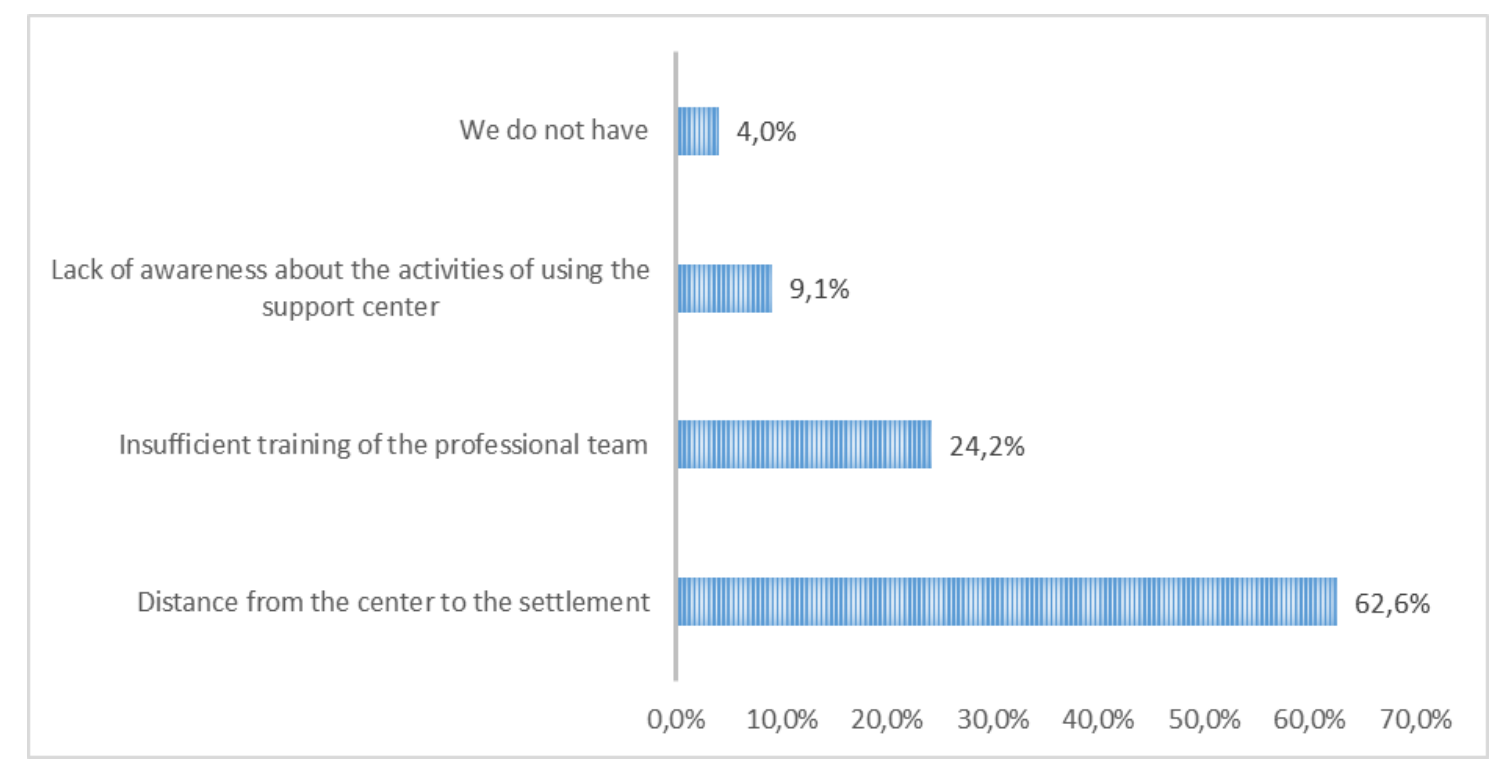

When asked how they try to overcome the difficulties, the answers given by the members of the multidisciplinary team are worrying in the sense that the majority of the respondents $(19.5 \%)$ think that these problems are anyway impossible to overcome. Some of them think that transport provision (15.9\%), both applying to the principal and the supervisor (15.9\%) and consulting and cooperating with different specialists (15.9\%) can solve the difficulties that arose. While only $6.1 \%$ of the respondents referred to the manifestation of patience, and $8.5 \%$ referred to the visit to the school by the specialists of the regional center. It is noteworthy that when perceiving the difficulties, the participants mainly imagined it within the school and did not view it as a problem that arises in the regional center or as an infrastructural problem (see Figure 11). 


\section{Figure 11.}

\section{Ways of overcoming existing difficulties.}

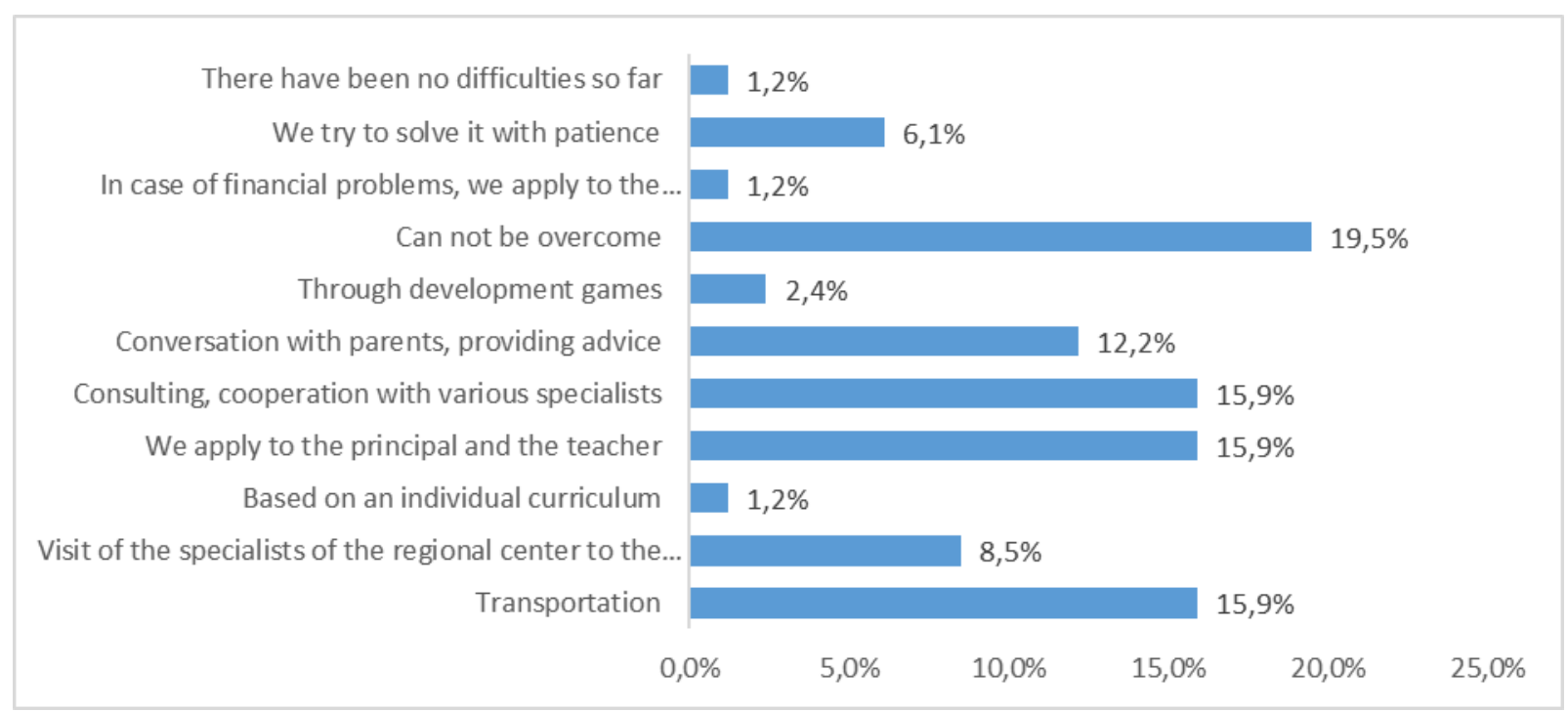

Quantitative analysis of the use of educational standards and support manuals that are important during the multidisciplinary team's activities shows that the majority of professionals (39.4\%) prefer the "Development and Education Standards for 0-6-year-olds", $20.2 \%$ give a lot of attention to "Standards for children with mild to moderate mental problems" or other textbooks in the process of organizing their activities, $11.1 \%$ mainly use the "Inclusive Education" teaching guide and the book "Special Pedagogy". 11.1\% of the respondents mentioned different professional literature, respectively, while the International Classification of the WHO Function indicated 3\% of the respondents, and the general education standards $1 \%$. It is also noteworthy that $4 \%$ of respondents are convinced that there is no educational standard (see Table 4).

By the way, let us state that the application of the "Standards for the development and education of a child aged 0-6", which is highlighted by the multidisciplinary team, was incomprehensible in this context, first of all for the simple reason that "Standards for the development and education of children from birth to 6 years" (It is noteworthy that this is the correct title of the mentioned criteria, which none of the respondents was able to formulate in their answers) published with the financial support of UNICEF (UNICEF, 2018), which were approved in 2011 by the Ministry of Education, Science, Culture and Sports of the Republic of Armenia are not timely at all. In addition, both in terms of age-leading activities and in terms of preference, they cannot be a guideline and meet the requirements of the universal inclusive education standards; therefore, it was unclear for most professionals (39.4\%) to use these standards. 
Regarding the "Inclusive Education" teaching guide and the book "Special Pedagogy" published in 2015, the need for which was assessed by $20.2 \%$ of the surveyed specialists, we must state that in the first case the teaching guide published by the "Bridge of Hope" NGO is not an educational standard and is only a means of supporting the professional development process of training specialists in the field of inclusive education and teachers of secondary educational institutions. In the second case, referring to the book "Special Pedagogy" as a necessary educational standard, the respondents could not specify the authors of the book, the edition year, and its use as a standard or teaching aid.

The fact that the specialists providing pedagogical-psychological support were not even aware of the educational standards and the need to use them in their work, also stems from the negative position in the field that the activities of specialists in the field of special education are not prioritized within the framework of RA educational reforms giving preference to the functions of teacher assistants, and in practice trying to replace the work of a narrow specialist with specialists who are incomprehensible and do not have the appropriate qualifications. This is why most of the interviewed professionals did not even have information about the staff lists formed during the transition to universal inclusion, their work passports, and roles. This may be the reason why the interviewed specialists were not aware of their functions envisaged by the educational standards and did not have any legislative or legal orientation.

Accepting educational standards and teaching aids as guidelines, however, professionals single out their preferred and effective support methods for working with children with special educational needs. These methods are presented in the chart below, which shows that the main methods used are games development (23.5\%), conversation method (14.8\%), and art therapy $9.4 \%$. The data presented in the same table also show that many specialists at the support center had no idea what the so-called "method" was.

\section{Table 4.}

Responses regarding educational standards.

\begin{tabular}{|l|r|r|}
\hline & \multicolumn{1}{|c|}{ Percentage: } \\
\hline Various professional methodological literature & 11 & $11.10 \%$ \\
\hline Criteria for development and education of a child aged 0-6 & 39 & $39.40 \%$ \\
\hline Principles of inclusive education of the child & 3 & $3.00 \%$ \\
\hline $\begin{array}{l}\text { Criteria for children with mild to moderate mental problems, } \\
\text { other textbooks }\end{array}$ & 20 & $20.20 \%$ \\
\hline Games & 1 & $1.00 \%$ \\
\hline Individual curriculum & 3 & $3.00 \%$ \\
\hline Inclusive education teaching guide, special pedagogy book & 11 & $11.10 \%$ \\
\hline Speech therapy manuals & 1 & $1.00 \%$ \\
\hline Internet & 2 & $2.00 \%$ \\
\hline
\end{tabular}


General education standards

We do not have

International classification of WHO function

Total

\begin{tabular}{|r|r|}
\hline 1 & $1.00 \%$ \\
\hline 4 & $4.00 \%$ \\
\hline 3 & $3.00 \%$ \\
\hline 99 & $100.00 \%$ \\
\hline
\end{tabular}

The percentages are based on the answers, as each respondent could indicate several answers.

This is evidenced by such answers as: "... I cannot mention the method, individual lessons, various, oral questions, I create myself, didactic materials, professional literature, etc ..." (see Figure 12).

\section{Figure 12.}

Methods of support used while working with children with special educational needs.

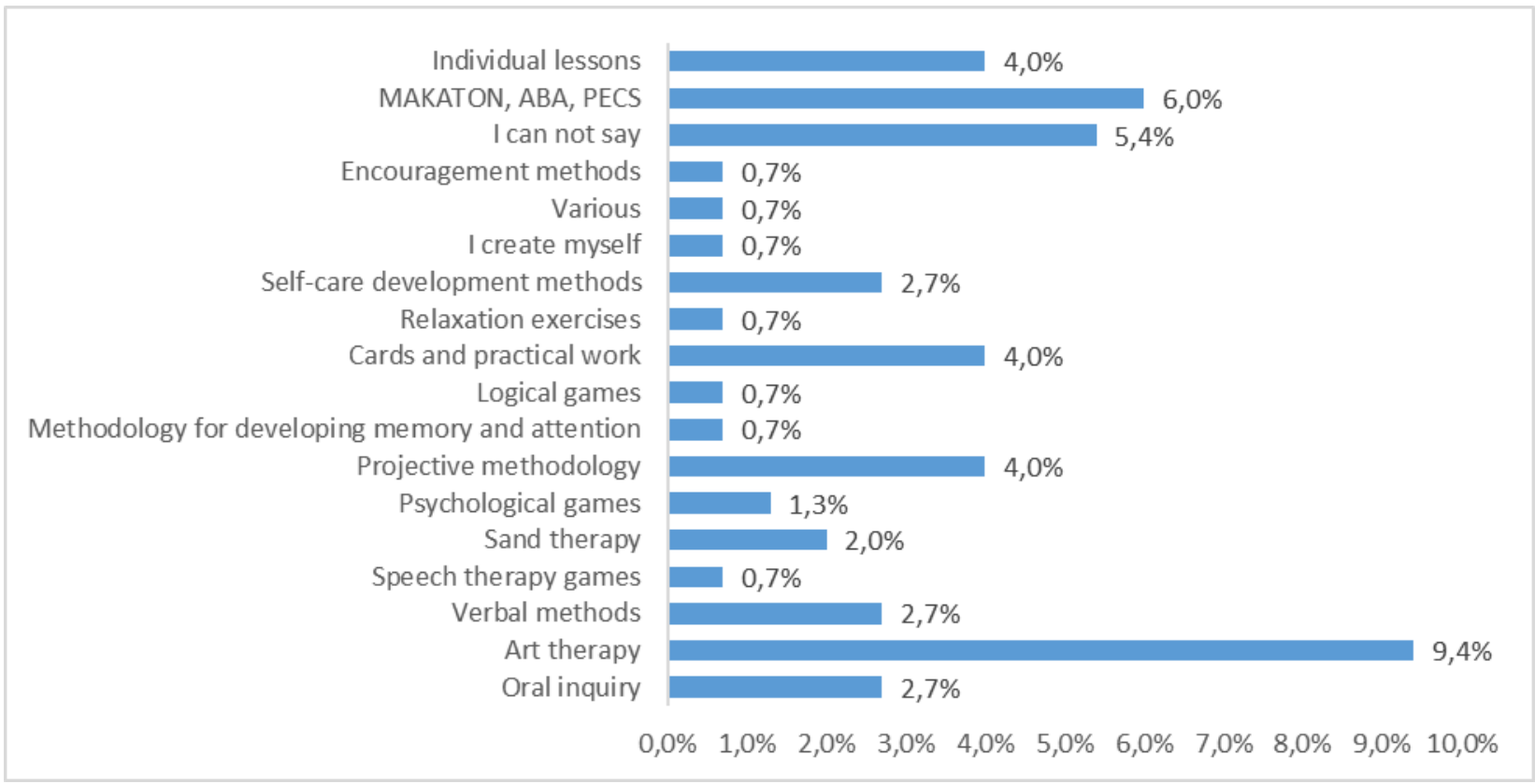

\section{CONCLUSION}

Thus, summarizing the presented quantitative analysis, it can be stated that support center visits to schools were also ineffective. Even according to them, getting to school is already a huge waste of time, which is impossible to avoid. Very often it is possible to support one child for only 15 minutes, which is certainly ineffective. Many answers from teachers and parents also testified to that. According to some specialists of the support centers, they are idle until 13:30, because "... there is no child with whom they have to work, instead they wait for the time to go to school..." At the same time, both support centers and school multidisciplinary team members have very low levels of professional knowledge. To the question of what resources are needed, specialists give vague answers, because they do not even know what 
didactic materials and methods should be used in the process of teaching children with special educational needs, what materials are needed. Or what special professional and educational games, toys, technical means, or educational and didactic items are there. They have no idea what kind of materials they need or how they can be used. Their lack of professional knowledge is also evidenced by the lack of coordination of their knowledge, abilities and skills, sometimes their complete ignorance. For example, the answer to the question "In case of development, which disorder do you have the most difficulty with?" It is not understood what skills he has as a specialist, what kind of work he lacks, or how his strengths are expressed. "Our work is not a problem for us ..." or "The school has a problem with intellectual disability, not us ..."

The mismatch between the small support team and a large number of certified children cannot be guaranteed quality pedagogical and psychological services. Support centers, mainly due to their inaccessible geographical location, not only deplete effective time management and professional potential, but also deprive many children of access to support centers, access to specialists, and bad weather or other external factors.

There are some problematic issues between support centers and parents related to the child's further education. There are serious conflicts with the parents, as the issues of further education of the child involved in inclusive education are not clarified. That is why parents avoid including their children in the above-mentioned system, they have even caused serious disagreements. They are often concerned only with the question of what will be written in the child's graduation certificate, whether they can continue their education in colleges or other educational institutions with that certificate. In addition, the order of attestation examination for such children is not clear, according to both the school teachers and their parents. Teachers and the school's multidisciplinary team, as well as teaching assistants, often encounter inconsistencies between assessment results and the child's actual abilities.

Also, there are differences in the procedure for providing support services in three regions of Armenia: Tavush, Lori and Syunik, which need to be regulated and clarified. It is worth stating, that the need for multidisciplinary teams and relevant specialists in schools was confirmed by the teachers, parents, and teachers' assistants at the school. Still, the education system is staffed mainly by female educators and the inclusion of male educators in the education system in this system and in general in connection with the upbringing of the generation is of paramount importance. 


\section{REFERENCE LIST}

1. Doody, O., \& Bailey, M.E. (2016). Setting a research question, aim and objective. Nurse Researcher. 23, 4, 19-23.

2. Harutyunyan, M., Hovyan, G., Saratikyan, L., Azatyan, T., Muradyan, S. (2019). Assessment of the process of universal inclusion in the RA Tavush, Lori and Syunik Regions.

3. Onwuegbuzie, A.J, \& Leech, N.L. (2006). Linking research questions to mixed methods data analysis procedures. Qualitative Report. 11, 3, 474-498.

4. Order N 370-N of the Minister of Education and Science of the Republic of Armenia of April 13, 2017 on approving the procedure for providing pedagogical-psychological support services for the organization of education.

5. Kloda, L.A, \& Bartlett, J.C. (2013). Formulating answerable questions: question negotiation in evidence-based practice. Journal of the Canadian Health Libraries Association. 34, 2, 55-60.

6. UNICEF, 2018. Tsnndic minchev vec tarekan erekhaneri zargacman ev krtakan chaporoshichner, Veranayvats $2018 \mathrm{tv}$.

Copyright (C) 2022 Published by Khachatur Abovyan Armenian State Pedagogical University \& the Authors

The article submitted and sent to review: 31.08.2021

Accepted for publication: 30.01 .2022 